\title{
La vulnerabilidad relacional: Análisis del fenómeno y pautas de intervención
}

\author{
Jordi Bonet i Martí \\ IGOP (Institut de Govern i Polítiques Públiques), UAB ${ }^{1}$
}

\section{Resumen}

En una sociedad cada vez más globalizada e interconectada, donde el paradigma del acceso tiende a sustituir el paradigma de la posesión y la disponibilidad de activos intangibles cobra una centralidad decisiva para explicar el poder y la centralidad social, los procesos de exclusión social no pueden ser explicados únicamente desde una perspectiva economicista (en función de la renta disponible) sino que devienen cada vez más una problemática relacional. En este sentido, los conceptos derivados del análisis de redes sociales pueden sernos útiles para profundizar en la comprensión de la dimensión relacional de la exclusión, tanto desde una perspectiva teórica basada en la comprensión del fenómeno, como desde una perspectiva aplicada que permita generar pautas de innovación en las respuestas a las necesidades derivadas. El objetivo de este artículo es combinar ambas perspectivas, partiendo de una investigación exploratoria desarrollada por el equipo EXURB del IGOP (Institut de Govern i Polítiques Públiques) de la Universitat Autònoma de Barcelona a fin de mejorar tanto nuestra comprensión de la vulnerabilidad relacional como apuntar posibles pautas de mejora del sistema de protección social, especialmente en el área de atención primaria.

Palabras clave: exclusión social, redes sociales, servicios sociales, psicología comunitaria.

\begin{abstract}
The purpose of this article is to explore the relational dimension of social exclusion. First, from a theoretical point of view, in order to get a better understanding of the phenomena. Second, from an applied point of view, in order to improve social services responses. The article is based in a research carried by EXURB team of IGOP (Institut de Govern i Polítiques Públiques) from Autonomous University of Barcelona. Social exclusion is a relational process that can't be explained only in economic terms. Social network analysis concepts may be useful to understand the phenomenon.
\end{abstract}

Key words: social exclusion, social networks, social services, community psychology.

\footnotetext{
${ }^{1}$ Enviar correspondencia a: jbonetma@uoc.edu
} 
Desde sus orígenes el Análisis de Redes Sociales (ARS) ha mantenido una clara orientación transdisciplinar, incorporando campos tan dispares como la psicología social, la antropología, la sociología estructural, la teoría de grafos y la economía. Sin embargo, en las universidades españolas, dónde todavía imperan los enfoques funcionalistas frente a los estructurales, continua siendo una disciplina poco cultivada. Paradójicamente, en las últimas décadas observamos en publicaciones científicas y divulgativas un auge del uso del término red. Lo relacional ha devenido una categoría emergente y numerosas obras científicas y de divulgación apelan a las redes como "metáfora" de lo social. Este uso (y abuso) del término conlleva aparejada una disminución de su potencial explicativo. Así cuando reducimos las redes a metáforas de los procesos sociales corremos el riesgo de generar categorías huecas, cuya inserción en una publicación científica sirve más como estilo retórico que como perspectiva analítica.

En el presente artículo, queremos realizar un desplazamiento respecto a esta perspectiva y analizar como en la práctica el ARS puede ser extremamente útil en el desarrollo de las investigaciones psicosociales actuales. A fin que este ejercicio no se reduzca a mera especulación teórica, hemos decidido ejemplificar su utilidad en el abordaje de los denominados procesos de 'exclusión social'.

En específico, nos interrogaremos acerca de qué puede aportarnos el ARS, y las teorías asociadas al mismo, para mejorar nuestra comprensión sobre los procesos de vulnerabilidad relacional asociados a la exclusión social; abordando esta cuestión desde un doble enfoque: teórico, como marco interpretativo para profundizar en la comprensión del fenómeno, y aplicado, como enfoque generador de pautas de intervención ${ }^{2}$.

Para ello hemos dividido el artículo en tres apartados: el primero, tendrá por objeto caracterizar la dimensión relacional de la exclusión social, un segundo, se centrará en las modelos de intervención actuales, para concluir en un tercero dónde se desarrollarán pautas para mejorar la capacidad de respuesta en el ámbito de la intervención social primaria frente a los nuevos retos que nos presenta la problemática analizada.

\footnotetext{
2 El artículo se basa en la investigación "La dimensión relacional de la exclusión social” desarrollada por el equipo EXURB del IGOP (Institut de Govern i Polítiques Públiques) de la Universidad Autónoma de Barcelona coordinada por el dr. Ismael Blanco Fillola y en que han participado como investigadoras además del autor del artículo: Gabriela del Valle Gómez, Uladimir Valdez, Anna Garriga como investigadoras. Agradezco a la dra. Barbara Biglia (Universitat Oberta de Catalunya) su constante apoyo, aportaciones y consejos en todas las sucesivas revisiones previas a su alumbramiento.
} 


\section{La vulnerabilidad relacional: una categoría emergente}

Los estudios acerca de la pobreza concebida como un estado asociado a la carencia de recursos económicos se habían centrado en establecer las líneas de pobreza, entendidas como el umbral de ingresos que permitía caracterizar a un segmento de la población como "pobre". Los recientes cambios estructurales asociados al proceso de globalización (auge de las tecnologías de la información y la comunicación; transformación de la estructura productiva, intensificación de los flujos migratorios sur-norte; alteración de la pirámide poblacional y transformación de las estructuras familiares) han alterado las rigideces del modelo de estratificación social dando lugar a una socialización del riesgo (Beck, 1986) y un incremento de los factores, dimensiones y colectivos que se encuentran en una situación de vulnerabilidad. A fin de dar cuenta de este fenómeno, los analistas sociales han optado por un cambio de paradigma explicativo, sustituyendo el tradicional concepto de pobreza por el de exclusión social, que por su carácter dinámico, procesual, multidimensional y multifactorial tendría mayor potencial explicativo que el precedente ${ }^{3}$.

Una de las consecuencias de la sustitución del paradigma explicativo de la pobreza por el de la exclusión social ha sido poner de relevancia su dimensión relacional. ${ }^{4}$ De hecho la incorporación de esta dimensión al estudio de la exclusión social tiene una larga tradición, que podemos rastrear en los estudios de Durkheim acerca del suicidio y en los de la Escuela de Ecología Urbana de Chicago. Sin embargo, no disponemos todavía de una perspectiva integrada que permita dar cuenta de la dimensión relacional de la exclusión social. Una aproximación al fenómeno de la exclusión no puede ser plenamente satisfactoria atendiendo únicamente a variables macro (renta familiar disponible, situación laboral, nivel de estudios,...) ni estrictamente micro (trayectoria biográfica del sujeto, estrategias de supervivencia,...) sino que tenemos que atender también a la importancia de las redes sociales con las que el sujeto interactúa.

\footnotetext{
3 Aunque nos permanezca la duda acerca de si el filtro interpretativo de la exclusión social no da carta de novedad a procesos que ya existían en situaciones anteriores catalogadas de pobreza, y sí esta opción teórica no puede llegar a invisibilizar o relativizar otras desigualdades.

4 Desde la perspectiva que adoptamos en el artículo consideramos que el concepto "exclusión relacional" es desafortunado en tanto que puede llevarnos a la confusión de considerar que haya exclusiones no relacionales. En este sentido, preferiremos el término vulnerabilidad relacional para referirnos a los procesos, modalidades y factores que modelan la dimensión relacional de la exclusión social.
} 
Esta demanda de nuevos enfoques de análisis, útiles a la comprensión de los procesos de exclusión social, que trasciendan la dicotomía micro-macro y la de estructura/acción conecta con uno de los argumentos basilares en la perspectiva del ARS: "la estructura de las relaciones sociales afecta al contexto de las relaciones que se pueden producir en la misma" (Requena, 2003), es decir, a partir del estudio de los patrones de regularidad en las relaciones que configuran la estructura de una red podemos alcanzar una mayor comprensión de los actores que intervienen en la misma, y a su vez las interacciones desarrolladas por estos actores no están sobredeterminadas por las estructuras en que se insertan, sino que tienen agencia para intervenir sobre las mismas.

Esta cambio de perspectiva, nos conecta con la teoría del embeddedness (Granovetter 1985, Coleman, 1988) según la cual la acción de los sujetos se encuentra inserta en un entramado de redes de relaciones sociales que le proporcionan acceso (o le impiden acceder) a determinados recursos e influyen en sus actitudes, comportamiento y cogniciones, así como las teorías del empowerment según la cual es posible activar procesos de fortalecimiento comunitario a partir de la coordinación de interacciones entre los distintos sujetos que participan en los mismos.

Dicho esto, creemos importante avanzar en una definición operativa de qué entendemos por vulnerabilidad relacional, que identificaremos como aquella situación generada por la ausencia o debilidad de los vínculos de inserción comunitaria.

Esta situación de vulnerabilidad puede caracterizarse básicamente en dos casuísticas paralelas:

- El sujeto se encuentra en situación de aislamiento o dispone solo de una débil red social de apoyo que no le permite disponer de vínculos de inserción comunitaria.

- El sujeto se integra una subred que se encuentra marginalizada de manera que no dispone de suficientes vínculos de inserción comunitaria.

Mientras la primeras casuística se encuentra ya analizada en los estudios tradicionales sobre exclusión social, la incorporación de la segunda intenta dar cuenta del hecho que el aumento de la fragmentación social asociado a la debilitación de los mecanismos de integración, conlleva la aparición de subredes segmentadas. La pertenencia a estas subredes, de por si minorizadas, excluidas o 
desvaloradas, se constituye como elemento que dificulta el acceso a los recursos disponibles en el espacio comunitario.

A fin de seguir avanzando en la comprensión de la vulnerabilidad relacional diferenciamos tres modelos de abordaje que consideramos útiles a fin de caracterizar la vulnerabilidad relacional:

\begin{tabular}{|l|l|l|}
\hline \multicolumn{1}{|c|}{ Aspectos estructurales } & \multicolumn{1}{|c|}{ Aspectos funcionales } & \multicolumn{1}{c|}{ Aspectos contextuales } \\
\hline $\begin{array}{l}\text { Tamaño } \\
\text { Densidad } \\
\begin{array}{l}\text { Poder y centralidad de los nodos } \\
\text { Cercanía y lejanía de la red }\end{array}\end{array}$ & $\begin{array}{l}\text { Tipología de los vínculos } \\
\text { Funcionalidad de la red para el } \\
\text { sujeto integrado (acceso a } \\
\text { recursos materiales, } \\
\text { informacionales, emocionales) }\end{array}$ & $\begin{array}{l}\text { Trayectoria histórica de la } \\
\text { red } \\
\text { Inserción y radicación en el } \\
\text { territorio } \\
\text { Estigmatización/Estimación } \\
\text { de la red }\end{array}$ \\
\hline
\end{tabular}

Tabla 1. Modelos de vulnerabilidad relacional

Este abordaje es innovador en cuanto amplia el análisis, añadiendo a la consideración de los aspectos estructurales, tradicionalmente analizados desde la perspectiva del ARS, los funcionales y los contextuales, que nos permitirán caracterizar la percepción de la red por parte del sujeto y de sus convecinos.

Desde esta perspectiva, y a partir del análisis realizado comprobamos que una situación de vulnerabilidad relacional viene caracterizada por la inserción del sujeto en redes vulnerables con un tamaño tendencialmente pequeño, una elevada densidad y débiles conexiones con otras subredes operantes en el territorio debido a la ausencia de brokers (nodos que ejercen de puente entre redes heterogéneas). A su vez comprobamos que estas redes vulnerables tienden a acentuar su homofilia (similitud entre nodos y tipología de los vínculos), con pocas variaciones estructurales e incapaces de satisfacer las necesidades de los sujetos que las conforman, lo que contribuye a aumentar el estress de la red, produciéndose situaciones de saturación y bloqueo de la red que analizaremos posteriormente. A su vez, estas circunstancias de vulnerabilidad tienden a agravarse en el caso de qué las redes se encuentren estigmatizadas como resultado de la extensión de prejuicios en el territorio. Finalmente cabe reseñar que los sujetos pueden encontrarse en redes vulnerables como resultado de trayectorias exclusógenas heredadas (pobreza familiar o estigma étnico heredado, por ejemplo en el caso de la población gitana) o a causa de fracturas relacionales que los exponen a situaciones de vulnerabilidad relacional.

En la siguiente tabla, a modo de resumen y sin voluntad de exhaustividad explicitamos algunos ejemplos de fracturas relacionales con las que nos hemos encontrado a lo largo de nuestro trabajo. 


\begin{tabular}{|l|l|}
\hline \multicolumn{2}{|c|}{ FRACTURAS RELACI ONALES } \\
\hline Migración/ Movilidad residencial & $\begin{array}{l}\text { Fractura con las redes de apoyo de origen y la necesidad de } \\
\text { recomponer las redes sociales en la sociedad receptora. En el } \\
\text { caso de migrantes hay que añadir las barreras lingǘsticas y los } \\
\text { prejuicios culturales con un posible grado de estigma. }\end{array}$ \\
\hline Separación conyugal & $\begin{array}{l}\text { Reducción de las redes de apoyo primarias (familiares, } \\
\text { amistades,...) }\end{array}$ \\
\hline $\begin{array}{l}\text { Mortalidad de familiares y/ o } \\
\text { amistades cercanas }\end{array}$ & $\begin{array}{l}\text { Reducción (o eventual extinción) de las redes de apoyo } \\
\text { familiares y de amistad. }\end{array}$ \\
\hline Matrimonio & $\begin{array}{l}\text { En los casos en los que la pareja no quiera que se mantengan } \\
\text { los vínculos con la familia de origen y/o con las amistades de } \\
\text { larga duración. }\end{array}$ \\
\hline $\begin{array}{l}\text { Accidente, discapacidad, } \\
\text { enfermedad crónica, dependencia }\end{array}$ & $\begin{array}{l}\text { Pérdida de autonomía, mayor dependencia de la red de apoyo } \\
\text { con riesgo de saturación y dificultad de generar nuevos } \\
\text { vínculos sociales. }\end{array}$ \\
\hline Tóxico-dependencias & $\begin{array}{l}\text { Inserción en redes con un bajo nivel de integración } \\
\text { comunitaria, cargadas de estigma social y posible fractura con } \\
\text { las redes familiares, amistad y ocupacionales anteriores. }\end{array}$ \\
\hline Pérdida de empleo & $\begin{array}{l}\text { Fractura con la red de apoyo en el ámbito sociolaboral y } \\
\text { posible situación traumática que repercute en la vinculación del } \\
\text { sujeto con sus redes primarias. }\end{array}$ \\
\hline $\begin{array}{l}\text { Violencia doméstica y situaciones de } \\
\text { malos tratos }\end{array}$ & $\begin{array}{l}\text { Reducción e invasión/control de las redes primarias del sujeto } \\
\text { por parte del agresor asociadas a situaciones de dependencia y } \\
\text { situación de pérdida de la significancia vital. }\end{array}$ \\
\hline Internalización & $\begin{array}{l}\text { En el caso de la hospitalización fragilización de las redes } \\
\text { primarias y desconexión con las redes comunitarias. En el caso } \\
\text { de residencialización añadir posible sentimiento de abandono y } \\
\text { desarraigo comunitario y en el caso de internamiento } \\
\text { penitenciario se le incorpora al estigma social y la dificultad de } \\
\text { recomposición de las redes una vez obtenida la libertad. }\end{array}$ \\
\hline
\end{tabular}

Tabla 2. Fracturas relacionales

El análisis de las fracturas relacionales conlleva la necesidad de adoptar una perspectiva longitudinal en el análisis, lo que implica cotejar los datos obtenidos en el análisis de las redes personales (egoredes) con la trayectoria biográfica del sujeto a fin de comprender circunstancias y factores exclusógenos que han llevado al sujeto a una situación de vulnerabilidad relacional. Consideramos que el análisis de las fracturas relacionales, que aquí solo hemos esbozado, consituye una dimensión clave en el abordaje (tanto teórico como aplicado) de la vulnerabilidad relacional, en tanto que representa un factor de ruptura en el espacio relacional del sujeto y a menudo se encuentra asociado a situaciones traumáticas con un fuerte impacto psicosocial. 
A partir del estudio de los perfiles de exclusión social (Subirats, 2005) y en concordancia con lo expuesto anteriormente (conjugando aspectos estructurales, funcionales y contextuales de la dimensión relacional), hemos desarrollado un modelo de categorización que resume cinco modalidades de exclusión relacional, su caracterización y los colectivos vulnerables asociados a las mismas. Aún y así, hay que tener en cuenta que presentemos este modelo solo por su carácter ejemplificador, ya que su desarrollo se encuentra todavía en una fase preliminar y requerirá una mayor profundización en el análisis así como una mayor variedad de datos.

\begin{tabular}{|c|c|c|}
\hline Modalidades & Caracterización & Colectivos vulnerables \\
\hline Aislamiento & $\begin{array}{l}\text { El sujeto deviene un } \\
\text { componente aislado de redes } \\
\text { sociales o familiares }\end{array}$ & $\begin{array}{l}\text { Homeless personas que se mueven en el } \\
\text { territorio sin hogar fijo } \\
\text { Población sobreenvejecida cuyas redes } \\
\text { sociales o familiares se han extinguido o } \\
\text { desconectado } \\
\text { Sujetos con minusvalia abandonados por } \\
\text { sus amigos y familiares }\end{array}$ \\
\hline $\begin{array}{l}\text { Debilitamiento de las } \\
\text { redes familiares }\end{array}$ & $\begin{array}{l}\text { Saturación de las redes de } \\
\text { apoyo familiar }\end{array}$ & $\begin{array}{l}\text { Personas con transtornos psíquicos o } \\
\text { enfermos crónicos } \\
\text { Población sobreenvejecida } \\
\text { Parados de larga duración (familiriarización } \\
\text { de la pobreza) }\end{array}$ \\
\hline $\begin{array}{l}\text { Debilitamiento de las } \\
\text { redes sociales }\end{array}$ & Redes sociales reducidas & $\begin{array}{l}\text { Mujeres con sobrecargas familiares cuya } \\
\text { disponibilidad para el cultivo de redes } \\
\text { sociales es reducida. } \\
\text { Parados de larga duración cuyas redes } \\
\text { sociales previas estaban vehiculadas por su } \\
\text { adscripción al lugar de trabajo. } \\
\text { Personas inactivas expulsadas del mercado } \\
\text { laboral con redes sociales reducidas al } \\
\text { entorno familiar } \\
\text { Personas con mobilidad reducida cuyas } \\
\text { redes sociales se ven reducidas a su espacio } \\
\text { de mobilidad } \\
\text { Mujeres que están en un proceso de } \\
\text { violencia domestica activa con separación } \\
\text { del entorno social } \\
\text { Supervivientes de procesos de violencia } \\
\text { domestica que vienen aisladas por parte de } \\
\text { sus redes sociales abituales por haber } \\
\text { quebrado los mandatos de roles de género } \\
\text { Trabajadoras/es sexuales marginalizadas } \\
\text { y/o estigmatizadas por su entorno social. }\end{array}$ \\
\hline $\begin{array}{l}\text { Inserción en redes } \\
\text { marginadas }\end{array}$ & $\begin{array}{l}\text { El sujeto se encuentra } \\
\text { inserto en redes sociales } \\
\text { marginadas que giran } \\
\text { alrededor ya sea del } \\
\text { consumo de substancias } \\
\text { ilicitas, de la } \\
\text { microcriminalidad o de } \\
\text { empleos ilegales. }\end{array}$ & $\begin{array}{l}\text { Adolescentes en riesgo que abandonan los } \\
\text { estudios y se insertan en bandas o grupos } \\
\text { asociados con microcriminalidad } \\
\text { Tóxicodependientes cuyas redes sociales } \\
\text { circulan alrededor del consumo de } \\
\text { substancias tóxico-adictivas }\end{array}$ \\
\hline
\end{tabular}




\begin{tabular}{|l|l|l|}
$\begin{array}{l}\text { Inserción en redes } \\
\text { homogéneas con baja } \\
\text { integración comunitaria }\end{array}$ & $\begin{array}{l}\text { Existe una situación de } \\
\text { fractura o dislocación } \\
\text { respecto a la red de apoyo } \\
\text { original. }\end{array}$ & $\begin{array}{l}\text { Población migrante recién llegada, en } \\
\text { situación irregular o de habla no hispana } \\
\text { con riesgo de ser estigmatizadas } \\
\text { socialmente. }\end{array}$ \\
& $\begin{array}{l}\text { Minorías étnicas marginalizadas (p.ej. } \\
\text { población gitana) }\end{array}$ \\
\hline
\end{tabular}

Tabla 3. Modalidades de exclusión relacional

\section{Las políticas frente a la vulnerabilidad relacional}

Desde una perspectiva de análisis de redes es fundamental analizar todos los agentes que influyen en el desarrollo, la prevención y la erradicación de la exclusión social y, más en específico, en el abordaje de su dimensión relacional. A este respecto, las políticas públicas se constituyen como un actor neurálgico. Por esto cabe preguntarnos sí en España las políticas sociales son eficaces para afrontar la dimensión relacional de la exclusión social. Es decir, analizar si existe un gap entre las demandas relacionales emergentes y las respuestas del sistema de protección social.

No obstante, debido al proceso de descentralización autonómica en el ámbito de protección social y al rol cada vez más predominante de la administración local en el diseño y ejecución de planes de intervención social, no podemos hablar de un único modelo sino de un mosaico de situaciones, a consecuencia de su elevado grado de fragmentación, por lo que difícilmente podemos dar una respuesta sencilla y general al interrogante planteado, sino que habría que realizar un análisis complejo y cruzar los resultados dado que esta problemática requeriría un amplio desarrollo que no estamos en grado de satisfacer en este artículo. Aún y así, podemos trazar un esquema de qué tipo de políticas y actuaciones pueden satisfacer en mayor grado las necesidades derivadas de la vulnerabilidad relacional y cuáles son inoperantes o incluso pueden llevar a agravarla.

En primer lugar, es necesario esbozar brevemente las principales características del sistema de protección social española partir de la caracterización de los regímenes de bienestar expuesta por Esping Andersen (1990) y completada en su modalidad meridional por el denominado "régimen de bienestar mediterráneo" caracterizado por: una corta tradición democrática que tiene su inicio en la Transición; una baja tasa de desmercantilización; un bajo nivel de gasto social; la universalización de la sanidad y la educación (excluyendo las guarderías) y finalmente un fuerte componente familiarista que tiende a absorber las deficiencias en prestaciones y servicios del estado desplazando su carga a las mujeres, que continúan siendo quienes desarrollan mayoritariamente las tareas asociadas a la esfera reproductiva. 
Por último, en relación al capital social el régimen de bienestar en España se caracteriza por fuertes formas de capital social bonding, ${ }^{5}$ (p.ej. la fortaleza de las redes familiares), y un bajo nivel de formas bridging, ${ }^{6}$ (caracterizado por un débil tercer sector y pocas iniciativas de concertación público-privada incluyendo las tres esferas mercado, sociedad civil y administración), especialmente en lo referido a la acción social.

Más aun, en los Servicios Sociales de Atención Primaria, persiste la herencia de una fuerte tradición histórica asistencialista, influida por el benificialismo católico, que ha restringido su campo de acción a 'poblaciones pobres' o 'fuertemente necesitadas', que si bien empieza a ser superada, especialmente en el campo profesional, todavía impregna el discurso público y la actuación de algunas instituciones. En este sentido y a pesar de los notables avances de las dos últimas décadas, los servicios sociales españoles, distan mucho todavía de convertirse en el cuarto pilar del estado de bienestar, ${ }^{7}$ y siguen imperando los criterios de las políticas orientadas a colectivos concretos (targeting) frente a aquellas transversales y con orientación universalista (mainstreaming). De hecho, la necesidad de superar un modelo de Servicios Sociales franquista orientado a la beneficiencia, conllevó la introducción de pautas de racionalización, descentralización y normativización, que si bien fueron útiles para remontar los déficit heredados, aplazaron las iniciativas de orientación comunitaria hasta la década de los 90'. Fue solo entonces cuando la diversificación de las necesidades y las movilizaciones sociales mostraron la ineficacia del modelo burocrático y la urgencia por rescatar nuevas formas de intervención social en conjunción con un tercer sector emergente cada vez más emancipado de la jerarquía eclesiástica. Esto, en conjunción con la iniciativa vecinal, tuvo su plasmación en el surgimiento de planes comunitarios y otras iniciativas integrales de acción social comunitaria ${ }^{8}$ que pero no representan ni muchos menos la mayoría de los casos

A fin de situar nuestro modelo de análisis, nos centraremos en primer lugar en analizar la dificultad de satisfacer las necesidades derivadas de la vulnerabilidad

\footnotetext{
5 Bonding capital: "capital social de unión" que se fundamenta en redes densas tendencialmente homogéneas establecidas a partir de relaciones de confianza y generadoras de identidades colectivas.

6 Bridging capital: "capital social de puente" que se fundamenta en la interconexión de redes heterogéneas y que distribuye el acceso a los recursos fomentando la cooperación.

${ }^{7}$ Los otros tres pilares corresponderían a la educación, la sanidad y el sistema de pensiones.

${ }^{8}$ Discurso a parte merecerla el análisis de cómo estos planes, por una parte innovadores, han servido en algunos lugares de palanca para la fragmentación del movimiento vecinal y la reducción de sus potencialidades creativas.
} 
relacional desde el modelo tradicional de intervención social, que continua presente en diferentes administraciones locales, ya sea como modelo dominante o subterráneamente como resultado del peso de las inercias institucionales en los distintos niveles de gestión/ejecución.

Uno de los principales déficit de la capacidad de respuesta del modelo tradicional se basa en su concepción de los servicios sociales, como ventanilla expendedora de servicios (en su versión más burocrática) o como equipamiento dónde se desarrolla una relación dual entre un profesional capacitado y el cliente (en su versión más profesionalista).

Ambas perspectivas, la burocrática y la profesionalista, comparten una línea de actuación centrada en el caso individual, en qué el usuario/cliente es abstraído de su medio social (y de sus redes relacionales) y dónde la administración monopoliza la intervención social relegando a un rol residual el tercer sector y la ciudadanía. Estas acciones se acompañan generalmente por una orientación estrecha de la inclusión social que, tal como todavía hoy reflejan las distintas políticas de ingresos mínimos de inserción (IMI, PIRMI,...) que tienden a considerar como única vía de superación de la exclusión la inserción laboral, relegando la intervención en las “necesidades relacionales" al tercer sector ${ }^{9}$.

Desde el modelo tradicional, la intervención del tercer sector adquiere un rol residual (en la doble acepción del término): por una parte como actor relegado al segundo orden, por otra como receptor de aquellas poblaciones (excedentes) no cubiertas por los servicios sociales (inmigrantes, homeless, poblaciones de etnias minorizadas, ancianos, enfermos crónicos, jóvenes 'asociales' ...).

Esta asignación del rol de "camión escoba" de los servicios sociales no es propia solo del modelo tradicional, sino que ha sido en cierta medida actualizada y puesta al día por el nuevo paradigma liberal-tecnocrático, sustituyendo la "residualización" por la "externalización", lo que implica una mayor racionalización y tecnificación de la intervención social y reduciendo el grado de compromiso cívico del estado. Frente a estas dos opciones, basadas en un modelo asistencial, se han alzado dos alternativas de acción en las que el estado aumenta su compromiso cívico y facilita

\footnotetext{
${ }^{9}$ La concepción que reduce la inclusión social a la participación en el mercado de trabajo formal ocupa todavía un espacio predominante en las agendas políticas de los países europeas. Si bien la aparición de los denominados 'working poors' como resultado de la flexibilización y precarización del empleo y el fracaso del modelo del workfare aplicado en Estados Unidos que condiciona el acceso a prestaciones y servicios sociales al desempeño a actividades laborales de inserción, está reorientando los debates de la inclusión más allá de su subordinación a la esfera salarial.
} 
la capacitación de actores no estatales: el modelo de estado animador (Donzelot, 1994) y el de gobernanza local. La diferencia entre ambos modelos se basa en la mayor o menor centralidad del estado en su relación con los actores no estatales (tercer sector-mercado).

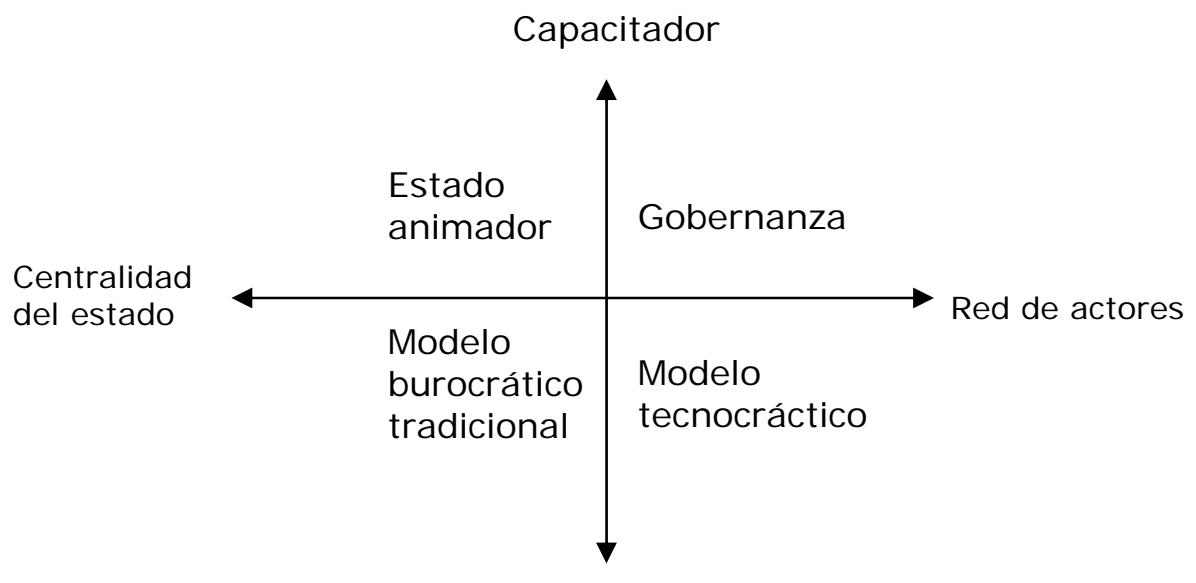

Asistencialista

I lustración 1. Modelos de provisión de bienestar

En el gráfico adjunto resumimos esta diferenciación de modelos de provisión de bienestar. En los cuatros cuadrantes encontramos diferentes modelos de actuación: el burocrático, que correspondería al gobierno tradicional; el tecnocrático, que se asocia con las democracias liberales que optan por una reducción del rol de las administraciones públicas externalizando la acción social sin generar procesos de empoderamiento ciudadano; el estado animador, típico de las democracias continentales (con especial incidencia en Francia), que empodera la sociedad civil manteniendo la centralidad y el control del estado y apoyándose en la provisión de recursos; y, finalmente, el de governanza local que empodera la ciudadanía, reconoce la dimensión territorial en su ámbito local y promueve el diseño participativo de las políticas de provisión de bienestar. No obstante las limitaciones que se puedan evidenciar, a nuestro parecer es este último modelo el que mejor se adapta a la construcción de satisfactores para abordar la dimensión relacional de la exclusión, en tanto que reconoce la naturaleza relacional de la generación de bienestar social, su dimensión territorial y opta por el fortalecimiento de los distintos actores imbricados (tanto los demandantes como los proveedores de recursos). 
A fin de visualizar las diferencias inter-modelos nos centraremos en la comparación entre el modelo burocrático tradicional y el modelo de gobernanza local por ser ambos los más relevantes en el diseño de políticas públicas locales en el estado español.

\begin{tabular}{|c|c|}
\hline Burocrático tradicional & Gobernanza local \\
\hline Ciudadano objeto de las políticas & Ciudadano sujeto de las políticas \\
\hline Orientadas a satisfacer necesidades & Orientadas a fortalecer capacidades \\
\hline Centradas en el individuo & Centradas en la comunidad \\
\hline Homogeneidad & Diversidad \\
\hline Estatista & Gobernanza en red \\
\hline Centralización & Descentralización \\
\hline Democracia delegativa & Democracia participativa \\
\hline Tecnocráticas & Aprendizaje Social \\
\hline Segmentador & Transversal \\
\hline Reactivas & Proactivas-Estratégicas \\
\hline A-territoriales & Reconocedoras dimensión territorial \\
\hline
\end{tabular}

Tabla 4. Comparación de modelos de políticas públicas

Con objeto de profundizar en como opera el modelo de gobernanza local respecto a la vulnerabilidad relacional en el ámbito local, distinguiremos tres niveles:

- Dimensión comunitaria: en esta dimensión incluimos las distintas redes sociales formalizadas (asociativas, económicas, administrativas) dónde interactúan distintos actores que ponen a su disposición los recursos y generan sinergias. Las líneas de actuación política en esta dimensión corresponderían a los planes comunitarios, fomento de parternariado, los consejos ciudadanos y la Responsabilidad Social Corporativa

- Dimensión mesocomunitaria: en esta dimensión incluimos el conjunto de redes sociales informales presentes en el territorio. Las líneas de actuación corresponderían a los distintos planes y acciones de mediación intercultural, programas de animación y dinamización sociocultural, programas de justicia restaurativa. 
- Dimensión microcomunitaria: en esta dimensión incluimos las redes primarias con que interactúa el sujeto. Las políticas correspondientes serían los programas de acompañamiento, políticas de buen vecino, servicios de atención domiciliaria y otros planes de atención a la dependencia, bancos del tiempo, programas de mediación comunitaria.

A fin de programar la acción social en un territorio que integre los tres niveles de actuación será necesario el diseño de herramientas de diagnóstico territorial que incluyan la dimensión relacional. En este sentido, consideramos que el ARS, tanto en su perspectiva de análisis de redes sociales (sociocéntrica) como de redes personales (egocéntrica) puede ser extremamente útil en el diseño y evaluación de programas, como técnica integrada en metodologías dirigidas a fomentar el empoderamiento (p.ej. Investigación-Acción-Participativa). Así pues, consideramos que la incorporación del ARS aumenta la potencialidad descriptiva y explicativa de los fenómenos de exclusión y permite generar pautas de intervención que rompen con una concepción orientada al caso individual.

En la literatura de redes destacamos dos aportaciones substantivas cuya importancia es fundamental para el abordaje de la intervención en la dimensión relacional: la teoría de los vínculos débiles de Granovetter (1973) y la de los agujeros estructurales de Burt (1982) A menudo, la adopción de un enfoque relacional en la intervención social se ha centrado en las redes que articulan el grupo primario (redes familiares, redes de amigos) dónde se concentrarían los vínculos fuertes, que presentan una elevada densidad en la estructura social y que constituyen los alteri con quien el sujeto interactúa con mayor frecuencia. Las redes personales "están constituidas por un centro de lazos fuertes que cambia lentamente a lo largo de la vida y una periferia más amplia y dinámica de lazos débiles" (Molina, 2005b)

Sin embargo, tal como constatan diferentes estudios, esta zona central de las redes personales es más vulnerable a las situaciones de saturación, en las que el sujeto no alcanza a satisfacer sus necesidades informacionales, materiales y emocionales en los recursos accesibles desde el grupo primario. Estas situaciones generan un incremento de stress en la red, que puede adoptar formas conflictuales, bloqueos o una percepción negativa de la misma por parte de sus integrantes. A su vez, frente a una situación de red stressada, si los Servicios Sociales de Atención Primaria ejercen el rol de único gatekeeper (guardián/puerta de acceso) a determinados recursos, aumenta el riesgo de generar dinámicas de "puerta giratoria" en las que se establece una relación de dependencia entre el sujeto y el servicio, dificultando 
el desarrollo de la autonomía personal y situando al sujeto en la condición de “permanentemente en inserción"10.

En este sentido y de acuerdo con la teoría de la fortaleza de los lazos débiles de Granovetter (1973), consideramos que una intervención social eficaz tendría que ser aquella que vaya más allá de la intervención centrada en los vínculos fuertes, para alcanzar a aquellos "conocidos" que pueden ejercer el papel de puente entre redes heterogéneas.

En este contexto, la labor de los profesionales de la atención primaria tiene que incorporar la tarea de facilitar al sujeto una mejor optimización de sus redes de familiares y amigos para aprovechar sus vínculos débiles de manera que puedan acceder a aquellos recursos que no puedan ser satisfechos por sus redes primarias, - acompañarle en su estrategia de generación de capital social relacional, disminuyendo así la dependencia institucional. Se trata de un cambio de mirada, dónde la red no se analiza únicamente como problema sino como oportunidad.

Este protocolo de respuesta, sin embargo nos sitúa todavía en una intervención atomizada centrada en el individuo, la adopción de un enfoque de redes en la intervención social precisa incorporar un enfoque que coimplique la activación de otros segmentos de la red. La adopción de un diseño de intervención social personalizada desde la perspectiva relacional pasa por atender las necesidades del sujeto a partir de la incorporación de las redes en que se encuentra inserto en la construcción de los satisfactores relacionales. Se trata de un trabajo de fortalecimiento de la capacidad de red de apoyo del sujeto para optimizar su capacidad de respuesta.

Sin embargo, esta perspectiva debe ser complementada con el trabajo a otro nivel. Las redes con las que interactúa el sujeto no se encuentran suspendidas en el vacío social sino que se encuentran incrustadas en un territorio dónde operan distintas redes (comunitarias, mercantiles, institucionales...) sobre las que se puede intervenir. Es en este territorio dónde operan los procesos de segmentación, estigmatización. Por ello una acción social primaria integral tiene que ir acompañada con planes y políticas de acción comunitaria que tengan por objetivo

\footnotetext{
${ }^{10}$ Esta situación de dependencia ha sido denunciada por Robert Castel respecto a los usuarios de las Rentas Mínimas de Inserción en Francia, cuya permanente ubicación en el "limbo de la inserción" ha llegado a generar una denominación específica para los mismos (los RMI istas) eternos clientes de los cursos y programas de inserción laboral con escasas posibilidades efectivas de integración continua en el mercado de trabajo.
} 
revalorizar la estructura de oportunidades formadas por la intersección de las distintas redes operantes a fin de generar dinámicas de inclusión territorial.

En este sentido, el profesional de la intervención social junto a los distintos actores e instancias coimplicadas adopta así un enfoque estratégico en su relación con las redes sociales en el territorio. Su labor pasa por un trabajo de diagnóstico e intervención relacional en el territorio incluyendo el análisis de los agujeros estructurales (Burt, 1982) presentes entre las distintas subredes y como estos pueden llegar a suponer una oportunidad para la intervención, tejiendo mallas de apoyo social y activando conexiones entre las distintas subredes operantes.

La labor de diagnóstico estratégico precisa a su vez de la generación de indicadores de bonding capital y de bridging capital. Tarea que desborda las posibilidades de ser realizada enteramente por profesionales de los servicios sociales y que precisa la conjunción de otras experticias proporcionadas por asociaciones, entidades así como la incorporación de expertos vivenciales, lo que implica la identificación y coaptación de actores en la producción de bienestar que dispongan de una elevada capacidad de ejercer de puentes entre relaciones para mediar entre distintas redes y facilitar el acceso a los recursos. Así como la identificación de aquellos espacios reticulares dónde se concentran las formas bonding de capital social a partir del establecimiento de relaciones de confianza que permitan generar significatividad y cohesión en el territorio.

En este sentido, podemos caracterizar una intervención social efectiva como aquella que tienda a mantener las formas bonding que aumentan la confianza y la dimensión cognitiva de reconocimiento mientras se incrementa el capital social bridging a partir de una optimización de los agujeros estructurales y la generación de vínculos débiles con redes heterogéneas. En este contexto, el profesional en intervención primaria tiene que incluir en su diagnóstico no solo el conocimiento de la red personal del sujeto (tamaño, densidad, funciones y percepción social de la misma), sino tambien las formas de capital social a las que tenga acceso en su ámbito territorial de proximidad. De esta manera, su intervención tendría que dirigise tanto hacia el fortalecimiento de la egored del sujeto como a un aprovechamiento de las oportunidades ofrecidas por el territorio.

Finalmente, cabe añadir que gran parte de las temáticas abordadas en este artículo están incluidas ya en el quehacer diario de muchos profesionales de la intervención social; cuya confrontación con la cotidianidad les empuja a desarrollar pautas de intervención cada vez más ancladas en la dimensión relacional y la explotación del 
trabajo en red. Así pues, en muchos casos es la combinación de la experticia tácita de estos profesionales junto a las estrategias de supervivencia de base familiar/informal quines cubren el gap entre las políticas sociales y las demandas vinculadas a las vulnerabilidades relacionales. Sin embargo, sería deseable que no fueran otra vez ellas ${ }^{11}$ quienes resolvieran los déficits, sino generar un mayor compromiso cívico de las administraciones públicas y el resto de actoresproveedores de bienestar a fin de dar satisfacción a las demandas relacionales surgidas de los procesos de exclusión social.

\section{Bibliografía}

Beck, Ulrich (1986). La sociedad del riesgo: hacia una nueva modernidad. Barcelona: Paidós.

Burt, Ronald y Towards, S. (1982). A structural theory of action: Network models of social structure, perception, and action. New York: Academic Press.

Coleman, James (1988). "Social Capital in the creation of human capital". American J ournal of Sociology № 94 pp 95-120.

Donzelot, Jacques (1994). L'état animateur. Essai sur la politique de la ville, París: Ed. Esprit.

Esping-Andersen, Gosta (1990). The Three Worlds of Welfare Capitalism. Cambridge: Polity Press.

Granovetter, Mark (1973). "The strength of weak ties". American Journal of Sociology. №78 pp. 1360-1380.

Granovetter, Mark (1985). "Economic action and social structure: the problem of embeddedness." American J ournal of Sociology. №91 pp. 481-510.

Molina, José Luís (2005a). “El estudio de las redes personales: contribuciones, métodos y perspectivas" Empiria, 16 pp.71-106.

Molina, José Luís (2005b). “La estructura social de la memoria” en Lozares C. (ed.) Interacción, Redes Sociales y Ciencias Cognitivas. Barcelona: La Razón Áurea (en prensa), con Chris McCarty, Claudia Aguilar y Laura Rota.

Navarro, Silvia (2004). Redes sociales y construcción comunitaria. Creando (con)textos para una acción ecológica. Madrid: Editorial CCS.

Navarro, Silvia (1999). "La red comunitaria como escenario y agente de prevención" Revista Redes. Servicios Sociales: Diputación de Huelva: Huelva №6 pp. 3-15.

\footnotetext{
${ }^{11}$ Resaltamos aquí el femenino por el elevado grado de feminización en las actividades profesionales relacionadas con la intervención social, lo que nos abre un importante campo de reflexión que la incorporación de la dimensión relacional ensancha todavía más.
} 
Requena, Félix (2003). Análisis de redes sociales. Orígenes, teorías y aplicaciones. Madrid: CIS.

Riva, Fernando de (1997). “La asignatura pendiente de la participación ciudadana en las políticas sociales" Revista Redes. Servicios Sociales. Diputación de Huelva №2 pp. 5-11.

Subirats, Joan (dir) (2005) Perfils d'exclusió social urbana a Catalunya: una aproximació qualitativa. Bellaterra: Universitat Autònoma de Barcelona. 